\title{
Application of GIS spatial regression methods in assessment of land subsidence in complicated mining conditions: case study of the Walbrzych coal mine (SW Poland)
}

\author{
Jan Blachowski ${ }^{1}$ (D)
}

Received: 26 August 2015/ Accepted: 14 July 2016/Published online: 21 July 2016

(C) The Author(s) 2016. This article is published with open access at Springerlink.com

\begin{abstract}
Land subsidence in the area of the city of Walbrzych (SW Poland) has been a consequence of underground mining of hard coal. Exploitation of multiseam deposit took place for several 100 years and ended in the late 90'ties of the twentieth century. During this time, many buildings and constructions were affected by subsidence-related damages and new landforms including mining waste dumps have developed on the surface in a consequence of underground extraction of coal. Previous studies indicated that cumulative subsidence calculated with the empirical Knothe theory reached $-22 \mathrm{~m}$, whereas calculations based on results of cartographic data processing showed more than $-30 \mathrm{~m}( \pm 3 \mathrm{~m})$ pointing to insufficient reliability of traditional methods when applied in complex and complicated conditions (multiseam and steeply inclined deposits). Present-day height of manmade landforms in areas affected by subsidence reaches $63 \mathrm{~m}( \pm 3 \mathrm{~m})$. Therefore, in the presented research, a weighted spatial regression method has been proposed for analysis and modelling of mining induced land subsidence. The study concerned the former Walbrzych coal mine area and the 1886-2009 period. The subsidence modelling has been done in geographic information systems with geographically weighted regression (GWR) method that allows for spatial variability of subsidence factors. Four, out of the analysed seven, subsidence factors were identified as significant (thickness, inclination and depth of coal levels and surface slope) and used as independent (explanatory) variables in construction of the subsidence model with the GWR method. The validated model was used to estimate subsidence in up to now unmapped areas transformed by manmade landforms. The maximum predicted subsidence in these parts for the 1886-2009 period reaches $-10.5 \mathrm{~m}$. In the result, a spatial representation (hybrid map) of subsidence for the entire Walbrzych coal mine has been produced.
\end{abstract}

Keywords Coal mining · Subsidence $\cdot$ Prediction · Spatial regression · GWR · GIS

Jan Blachowski

jan.blachowski@pwr.edu.pl

1 Faculty of Geoengineering, Mining and Geology, Wroclaw University of Science and Technology, Na Grobli 15, 50-421 Wrocław, Poland 


\section{Introduction}

Subsidence is a time-dependent deformation of the ground's surface caused by readjustment of the overburden above voids created by underground extraction of minerals. Mining-related subsidence may lead to subsidence-related damages to surface infrastructure, buildings, engineering structures, farmlands, as well as interrupt the balance of underground water levels, and natural and manmade surface drainage systems. The shape of the subsidence area can be described with basic deformation parameters: vertical and horizontal displacements, tilt, radius of curvature and horizontal strain that provide quantitative information on the possible hazard caused by surface deformation. The character of mining subsidence depends upon many factors such as: location and geometry of mined deposit (e.g. inclination, thickness), depth of mining, production methods, local geological and tectonic conditions, duration of mining and underground operating speed (Kratzsch 1983; Knothe 1984; Popiolek 2009). In many countries, systematic investigations of subsidence in underground coal mining fields to control its adverse effects on urbanisation have been conducted using field observations since the late nineteenth century (Kuşcu 1991). Numerous studies have also focused on developing methods for prediction of land subsidence and subsidence-related damage hazards. Recent publications on mining subsidence can be generally categorised into two groups, the first includes investigations concentrating on monitoring and observation of subsidence, and the second focuses on research into modelling and predicting subsidence and the related hazards to the surface and infrastructure. Current studies focusing on monitoring subsidence on mining grounds with geodetic (precise levelling, GPS) and modern remote sensing techniques include work by Raucoules et al. (2003) who have described application of differential InSAR (DInSAR) technique to detect and monitor ground deformation on a test site of underground exploitation of salt using solution mining method in France. They have shown that the geometry of the subsidence bowl is different and larger than the one assumed from groundbased geodetic measurements. Can et al. (2013) have investigated surface, mining related, deformations on engineering structures in a coal basin in Turkey with precise levelling and static GPS observations in a monitoring network. They have identified active and residual subsidence effects on selected engineering structures. Doležalová et al. $(2009,2012)$ have repeatedly observed subsidence caused by underground coal mining with GPS technique and analysed the time dependence between the mining subsidence and horizontal movements and the progress of exploitation. They have also combined GPS and DInSAR in investigations concerning the Karvina coal basin in the Czech Republic (Kadlečík et al. 2015). Samsonov et al. (2013) presented a methodology for integration of multiple InSAR data sets for computation of two-dimensional time series of ground deformation and applied it for mapping mining-related subsidence and uplift in the Greater Region of Luxembourg along the French-German border. Studies of former mining grounds in the Netherlands showed occurrence of surface deformations several decades after closure of underground mines. Observations of mining grounds with PSInSAR technique revealed differentiated character of movements including uplift and changes near tectonic faults. The authors (de Vent and Roest, 2013) point to risk of cavities as a result of shallow mining there. Dong et al. (2015) applied stacking and small baseline subset interferometric synthetic aperture radar (InSAR) techniques to perform spatiotemporal analysis of ground subsidence in a coal mining area in China. They have proved that results from InSAR are consistent with the ground levelling measurements and have used it for mapping long-term subsidence in that area. 
Recent studies focusing on modelling and predicting subsidence and subsidence damage hazard include work of Oh and Lee (2011) who have integrated the following four models: frequency ratio (FR), weights of evidence (WOE), logistic regression (LR) and artificial neural network (ANN) to identify and quantify relations between land subsidence location and seven related factors (slope, depth of drift, distance from drift, groundwater level, permeability, geology and land use) for the purpose of analysing ground subsidence hazards caused by abandoned coal mines in Korea. The relations were then used as factor ratings in GIS overlay analysis to create ground subsidence hazard indices and maps. In another study in Korea, Lee and Park (2013) and Park et al. (2014) have analysed land subsidence hazard caused by abandoned underground mines using the decision tree approach and factors that can influence subsidence in a geographic information system (GIS). They have produced and verified land subsidence hazard maps for the study site. Stecchi et al. (2012) studied ground deformation phenomena affecting a town in Bosnia Herzegovina as a consequence of underground salt deposits exploitation. They have proposed a multicriteria analysis approach to assess vulnerability of an area to subsidence damage. It has been based on GIS integration with an external application. Mathey (2013) has used GIS analytical functions to assess geotechnical risk associated with abandoned underground coal mines in South Africa. Malinowska (2014) applied the classification and regression tree theory (CART) for assessing damage to concrete buildings, caused by surface deformation and tested in on a mining site in Poland. She has based the method on six identified risk factors deciding for the occurrence of building damage (predicted horizontal strain, year of construction, number of stories, length of wall, function and protection). Sedlak (2015) has studied the problem of deformation vector estimation on magnesite mining grounds in Slovakia and developed a theory of specific solution of deformation vectors for this site.

This concise review shows that the problem of monitoring and modelling of mining subsidence and the related hazard to surface and infrastructure is a current scientific and practical issue. In this paper, a GIS-based weighted, spatial regression method is proposed to study mining-related land subsidence on the example of the former Walbrzych coal mines area in SW Poland. In a preceding study concerning this area, it has been found that traditionally used methods of mining subsidence modelling based on empirical assumptions, such as the Knothe theory (Knothe 1984), may provide results that are not always reliable for numerous, thin and steeply inclined coal seams (Blachowski and Milczarek 2014).

Geographically weighted regression (GWR) (Brundson et al. 1996; Fotheringham et al. 2002 ) is a method that allows to study how a given phenomenon (e.g. subsidence) varies spatially in a particular area. As the GWR takes into account local parameters, it can be considered as a spatial extension of multiple linear regression. The method, by taking into account spatial variability of mining subsidence factors, should provide better estimation of mining subsidence than global regression methods (e.g. ordinary least squares, OLS) or the above-mentioned empirical methods in case of complicated mining conditions. In addition, GWR can be used to predict subsidence in areas where surface displacement measurements are not available or too scarce for subsidence mapping. The method gains increasing attention and has been used in studies of economic, social and environmental phenomena that show spatial variability. The theory behind the GWR and its applications are described in Sect. 3 of this paper. In this study, GWR has been used to develop a spatial regression model to analyse relationships between subsidence (dependent variable in the model) and common mining subsidence factors (independent, explanatory variables in the model). The analysed mining subsidence factors included: location and thickness of coal panels, 
inclination and depth below the ground of coal panels, surface topography (elevation and slope), distance from coal parcels and mining system used.

The objectives of this study included: (1) identification of statistically significant mining subsidence factors, (2) construction of spatial regression models for mining subsidence in part of the Walbrzych coal mines, (3) assessment of global regression model (OLS) and GWR model for mapping mining subsidence in this area, (4) prediction of mining subsidence with the GWR model and (5) discussion of features and uses of the GWR method in spatial modelling of mining-related subsidence.

\section{Study area}

The study area covers $12.2 \mathrm{sq} \mathrm{km}$ of the central part of the former hard coal mining grounds associated with the Walbrzych coal mine in the city of Walbrzych located in SW Poland. The entire site is situated between longitudes $16^{\circ} 7^{\prime} 30^{\prime \prime} \mathrm{E}$ and $16^{\circ} 20^{\prime} 00^{\prime \prime} \mathrm{E}$ and latitudes $50^{\circ} 43^{\prime} 00^{\prime \prime} \mathrm{N}$ and $50^{\circ} 48^{\prime} 00^{\prime \prime} \mathrm{N}$ or $X=297,000 \mathrm{~m}$ and $X=312,000 \mathrm{~m}$ and $Y=319,000 \mathrm{~m}$ and $Y=329,000 \mathrm{~m}$ (EPSG 2180 coordinate system) (Fig. 1).

\subsection{Mining}

Underground mining of coal deposits in complex and complicated mining and geological conditions (numerous steeply inclined and thin coal beds) took place in Walbrzych for several 100 years and ended in the late 1990's when all of the mines closed down. After the World War II, three underground mines were in operation: Thorez/Julia, Victoria and Walbrzych. The following mining systems were used: long-wall and caving (predominant) and long-wall with various forms of fill (pneumatic, dry, dry with material from dead

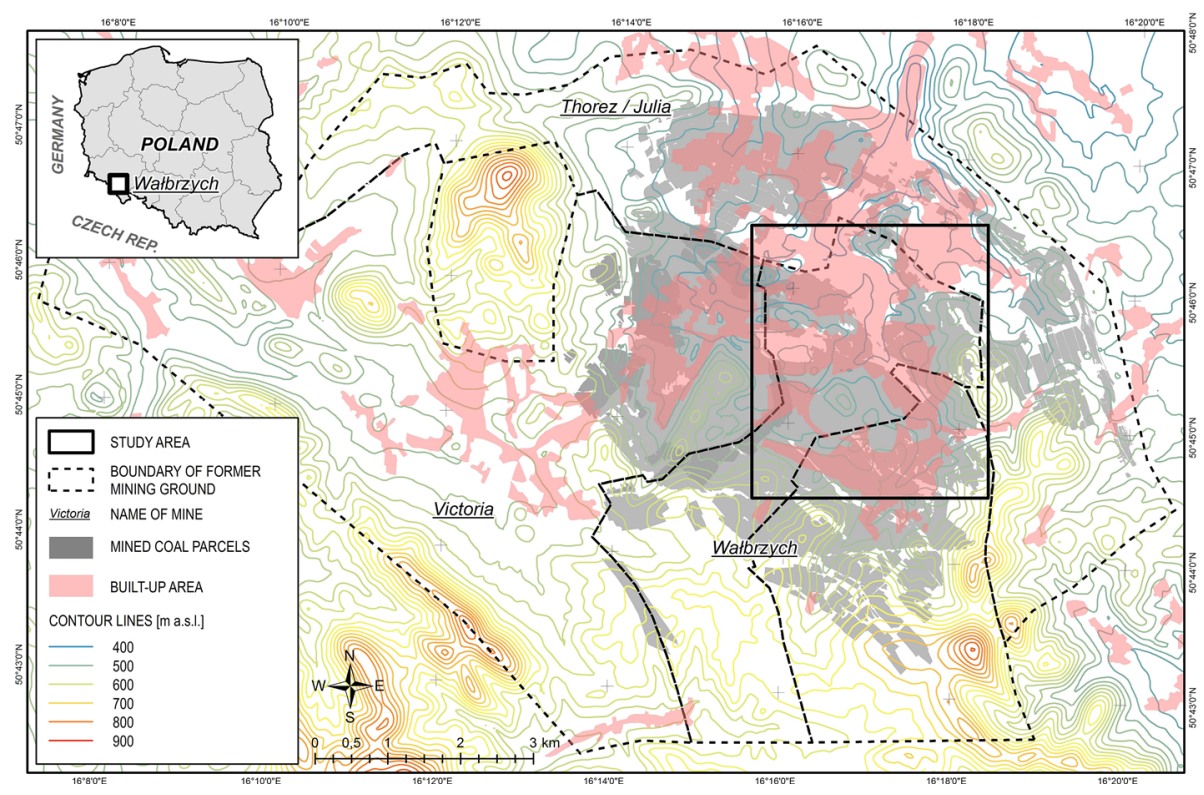

Fig. 1 Boundaries of former mining grounds and location of the study area 
drifts). The locations of underground coal panels and boundaries of the former mining grounds are shown in Fig. 1.

\subsection{Geology}

In terms of geology, the area is situated in the Walbrzych Basin-a geological structure constituting the NE part of the Intra-Sudetic Basin. It is differentiated in terms of the continuity of deposits, thickness of deposited formations and tectonic conditions (Kożuchowicz and Oprychał 1984). The main structural units of the basin are: the Jablowa anticline, the smaller Gorce and the larger Sobiecin synclines and the Chelmiec rhyolite laccolith separating the two synclines. The area is composed predominantly of sedimentary clastic deposits, as well as volcanic rocks such as: porphyry, melaphyre and tuff (Bossowski and Ihnatowicz 2006). The complicated geology is the results of intrusive and compressive tectonic activity of the Asturian phase. Most of the faults trend from NW towards SE with the influence of the Chelmiec intrusion clearly marked by longitudinal and latitudinal faults. The throw of the main faults reaches $300 \mathrm{~m}$. In addition, there are numerous local faults in the hard coal-bearing layers, with throws of several metres (Kominowski 2000). The Walbrzych coal basin is of a limnic type, where the deposition took place in intra-mountainous sedimentary basins. This has resulted is a mixed exogenous-endogenous coal deposit. The coal-bearing layers are associated with three of the four lithostratigraphic Pennsylvanian complexes: the Žaclér formations, the Biaty Kamień and the Walbrzych formations. Altogether, eighty coal seams have been identified, including 48 in the Žaclér formations and 30 in the Walbrzych formations. The stratal dips are towards the centre of the basin, ranging from several to over $30^{\circ}$, and from $30^{\circ}$ to $60^{\circ}$ in the outskirts (Kominowski 2000). In the analysed part of the area, 14 coal levels had been mined.

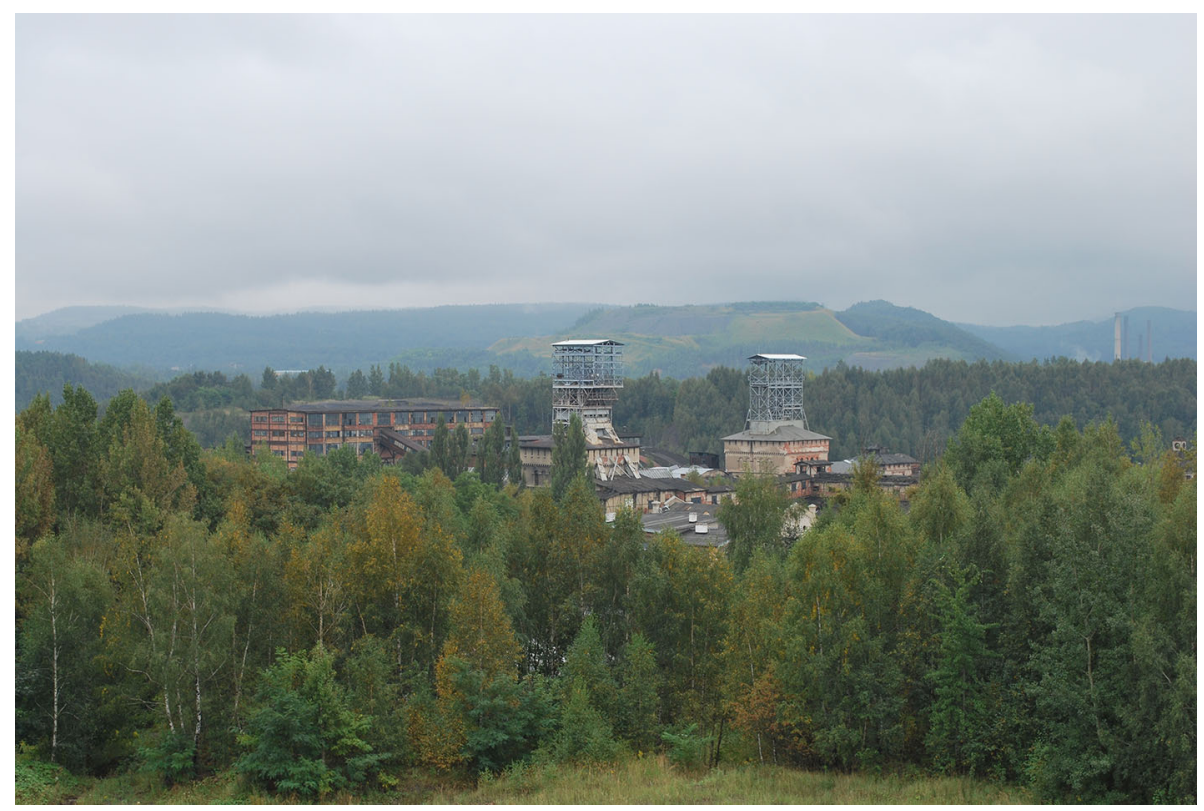

Fig. 2 Remains of the Thorez/Julia mine surface infrastructure-winding towers and manmade waste dumps in the background (photo J. Blachowski, 2013) 


\subsection{Topography}

The topography of the Walbrzych Coal Basin area is differentiated, with wooded hills, the largest being Mt. Chelmiec ( $851 \mathrm{~m}$ a.s.1.), separated by elongated valleys. The valleys are associated with the synclines mentioned earlier. Height differences between mountain tops and valley bottoms reach up to $420 \mathrm{~m}$. The long-time extraction of coal has caused large transformations of the original topography that include subsidence basins and the resulting damage to buildings and other types of infrastructure, as well as development of anthropogenic forms of terrain, such as: infrastructure associated with mining, settlement ponds and waste dumps. The latter, reaching up to $100 \mathrm{~m}$ above the ground, are often larger in size than the neighbouring natural forms of the terrain (Fig. 2). Subsidence basins resulting from underground mining developed mainly in larger natural depressions (valleys) and are sometimes difficult to detect apart from damages to buildings. Kowalski (2000) holds that the total subsidence during the entire period of mining might have reached $-22 \mathrm{~m}$. Wójcik (2008) estimates that 41.8 per cent of the former mining terrains has undergone transformation due to the effects of mining activity and notes, natural (Mt. Chetmiec) and anthropogenic (waste dumps, subsidence basins) inversions of topography.

\section{Methodology}

Spatial modelling of mining subsidence is a challenging problem due to the complexity of factors behind this process and the resulting spatial heterogeneity of variables. GIS spatial data processing techniques can be used to facilitate handling and processing large and numerous data sets required for subsidence modelling and GIS spatial data analysis methods can be applied to develop subsidence models and facilitate studies of this phenomenon. For example, regression analysis can be used to model the relationship between one variable (e.g. subsidence) and one or more other (explanatory) variables. Spatial regression methods may assume that these relationships are consistent geographically or take into account the spatial locations of features, permitting the estimated parameters to vary locally, thus better reflecting the spatially varying relationships between the dependent and independent (explanatory) variables. The ordinary least squares (OLS) method, which assumes that relationships are consistent geographically, is an example of the first. The geographically weighted regression (GWR), which allows to explore and analyse the spatial distribution of variables by fitting a regression equation to every point in space and thus study spatial heterogeneity and spatial relationships, is a representative of the second. The GWR provides a local model of the analysed or predicted phenomenon (dependent variable) and identifies the coefficients of variables at each location.

If the general multiple linear regression model may be written as (1) (Charlton and Fotheringham 2009),

$$
y_{i}=\beta_{0}+\beta_{1} x_{1 i}+\beta_{2} x_{21}+\cdots+\beta_{m} x_{m i}+\varepsilon_{i}
$$

where, $y_{i}$ is the dependent variable measured at location $I, x_{i}$ are the independent variables, $\beta_{i}$ are the model coefficients, $\varepsilon_{i}$ is the error, $i=1$ to $\mathrm{m}$.

Then, the GWR version of the OLS regression model is (2) (Charlton and Fotheringham 2009), 


$$
y_{i}(u)=\beta_{0 i}(u)+\beta_{1 i}(u) x_{1 i}+\beta_{2 i}(u) x_{2 i}+\cdots+\beta_{m i}(u) x_{m i}
$$

where the term $\beta_{O i}(u)$ indicates that the coefficient describes a relationship around location $u$ and is specific for that location. If measurements for the independent variables $x_{i}$ are available for the location $u$ then a prediction for dependent variable $y$ may also be made.

The theory behind spatial regression has been described by (Brundson et al. 1996; Fotheringham et al. 2002) and its implementation by Charlton and Fotheringham (2009, 2010).

There are relatively few publications of studies related to analysis of land subsidence with this method and probably none concerning mining induced subsidence. The work done by Shang et al. (2011) utilises GWR to explore the spatiotemporal changes based on the observed data of groundwater levels and benchmark elevations in an alluvial fan in central Taiwan and to examine the spatial heterogeneity. It revealed that occurrence and development of land subsidence is closely related to groundwater pumping, whereas Huang et al. (2013) applied OLS and GWR to build models between landslide surface displacement from monitoring data and trigger factors in ArcGIS for a site in Three Gorges Reservoir area of Yangtze River in China. Other uses of the method include mapping soil organic carbon stock in study carried out for the state of Pennsylvania (USA) that examined the relationships between environmental variables and soil organic carbon stock (Kumar et al. 2012) and household price estimations (Krivoruchko 2011).

In this study, a weighted spatial regression technique was used for hypothesis testing of variables that are likely to account for the calculated subsidence (dependent variable) in a period of 123 years (1886-2009) of mining in the Walbrzych coal mine area. The analysed subsidence factors (independent or explanatory variables) included: location and thickness of coal panels, depth of coal panels below the ground, inclination of coal panels, surface elevation, surface slope and distance from mined coal panels and mining system.

The research methodology consisted of the following steps:

1. Preparation of raster spatial representations of mining subsidence factors-dependent and independent variables for spatial regression analysis.

2. Exploratory analysis. Analysis of general spatial regression models and identification and selection of variables providing the best explanation for dependent variable (subsidence).

3. Construction and analysis of regression model with ordinary least squares (OLS) method.

4. Construction and analysis of geographically weighted regression (GWR) model with the same set of variables.

5. Comparison of OLS and GWR models, and analysis of GWR model performance.

6. Construction of subsidence prediction map with the GWR model.

\section{Analysis and discussion}

\subsection{Data preparation and preprocessing}

The study area represents the Walbrzych coal mine, one of three underground coal mines that operated in the region. Land subsidence for the analysed part has been calculated using the methodology presented in (Blachowski and Milczarek 2014). The subsidence map has been constructed by subtracting digital elevation model constructed from 1886 topographic 
map (1:10,000 scale Meßtischblatt from German Staatsbibliothek) and the present-day (2009) digital elevation model. Digital elevation model of the surface with $10 \mathrm{~m}$ horizontal and $1.5 \mathrm{~m}$ vertical resolution was generated through photogrammetric processing of aerial images and obtained from the Dolnoslaskie Voivodeship Documentation Centre of Geodesy and Cartography. For the study area, the maximum subsidence for the 123-year period is $-27.9 \mathrm{~m}$ and elevation is $+48.7 \mathrm{~m}$ calculated with accuracy of $\pm 3.0 \mathrm{~m}$ (Blachowski and Milczarek 2014). Areas of the latter are associated with anthropogenic forms of the terrain that have developed over time such as mining waste dumps.

The maps of mining subsidence factors (explanatory variables in the regression model) have been constructed from vector data representing coal parcels and coal seams as 3D ( $x y z)$ polygons with attribute information stored in the Walbrzych coal mines mining deformation information system (DIS) database. The database has been developed by coding to a vector format scanned mining maps, for the Walbrzych mine 274 plans drawn at scales 1:2000 and 1:5000 and spanning 200 years of underground coal extraction (Blachowski et al. 2014).

The analysed explanatory variables included: (1) thickness of coal panels, (2) depth below the ground of coal panels, (3) inclination of coal panels, (4) location and distance from coal panels, (5) digital elevation model of the surface, (6) surface slope and (7) mining system used.

All the spatial representations of possible explanatory variables have been prepared as raster maps with $10 \mathrm{~m}$ pixel size. The study area has been divided into $50 \times 50 \mathrm{~m}$ polygon mesh. Raster data sets of dependent and independent variables have been used to extract a particular variable values and assign them to spatially convergent polygons of the mesh used in spatial regression analysis. The simplified work flow of data preparation for spatial regression is shown in Fig. 3 and the final thematic maps of dependent (subsidence) and explanatory variables are shown in Fig. 4. The ArcGIS software ver. 10.2 licensed to Wroclaw University of Science and Technology has been used in the study.

Because of the complicated character of coal extraction, the following simplifications have been assumed. The depth of coal panels below the ground was calculated as the difference between the surface digital elevation model and the mean elevation of the 14 mined coal seams. The inclination of coal panels has been calculated as the mean inclination of all the coal panels.

\begin{tabular}{|c|c|c|c|}
\hline \multicolumn{4}{|c|}{ Source spatial data in the Walbrzych DIS database } \\
\hline \multicolumn{2}{|c|}{$\begin{array}{l}14 \text { coal panels mined in the } 1886-1996 \text { period } \\
\text { XYZ polygon geometry with attribute information } \\
\text { (e.g. mining system, coal level thickness) }\end{array}$} & \multicolumn{2}{|c|}{$\begin{array}{l}\text { - Surface digital elevation model (raster dataset), } \\
\text { - 1886-2009 subsidence (raster dataset) }\end{array}$} \\
\hline \multicolumn{4}{|c|}{ 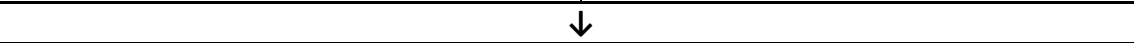 } \\
\hline $\begin{array}{l}\text { - Convert attribute data } \\
\text { to raster: } \\
\text { - Coal panel thickness, } \\
\text { - Mining system }\end{array}$ & $\begin{array}{l}\text { - Generate DEMs of } \\
\text { coal panels (raster) }\end{array}$ & $\begin{array}{l}\text { - Calculate euclidean } \\
\text { distance from coal } \\
\text { panels (raster) }\end{array}$ & $\begin{array}{l}\text { - Calculate slope of } \\
\text { surface DEM (raster) }\end{array}$ \\
\hline \multicolumn{4}{|l|}{ 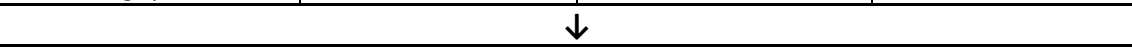 } \\
\hline \multicolumn{4}{|c|}{$\begin{array}{l}\text { - Calculate inclination and average inclination of coal panels (raster) } \\
\text { - Calculate depth and average depth of coal panels with map algebra }\end{array}$} \\
\hline \multicolumn{4}{|c|}{$\downarrow$} \\
\hline \multicolumn{4}{|c|}{$\begin{array}{l}\text { Assign values from rasters representing dependent and explanatory variables to spatial regression input } \\
\text { dataset - polygon mesh }(50 \mathrm{~m} \times 50 \mathrm{~m}) \text { - spatially convergent with maps of variables: subsidence, coal } \\
\text { thickness, ave. coal depth, ave. coal inclination, distance from coal panels, surface elevation and surface } \\
\text { slope, mining system }\end{array}$} \\
\hline
\end{tabular}

Fig. 3 Work flow of data preparation and preprocessing 
In the analysed part of the area, thickness of particular coal levels varies between 0.6 and $2.0 \mathrm{~m}$ and the total thickness of combined coal levels ranges from $0.6 \mathrm{~m}$ to $16.0 \mathrm{~m}$. The (averaged) inclination of coal panels is $1-85 \%$, whereas mean depth of coal panels changes from less than $20 \mathrm{~m}$ to over $700 \mathrm{~m}$ below the ground. Coal was extracted predominantly with the long-wall and caving method, and the mining system variable, statistically insignificant, has not been included in the final regression model.

The study area has been divided into two parts: the first one representing the area of calculated subsidence $(80 \%)$ and the second one representing the area of elevation calculated between 1886 and 2009 (20\%) (Blachowski and Milczarek 2014). The latter has also experienced mining-related subsidence in the analysed period but because of the development of anthropogenic landforms such as waste dumps it was not detected. The area of subsidence has been used to construct and validate the weighted spatial regression model that describes the mining subsidence basin. The model has been then applied to the region of elevation to determine the subsidence that has occurred in this part of the study area. The extent of both zones is shown in Fig. 5. The area of calculated subsidence consisted of 3361 square polygons, and the area of prediction constituted of 839 irregularly grouped square polygons.
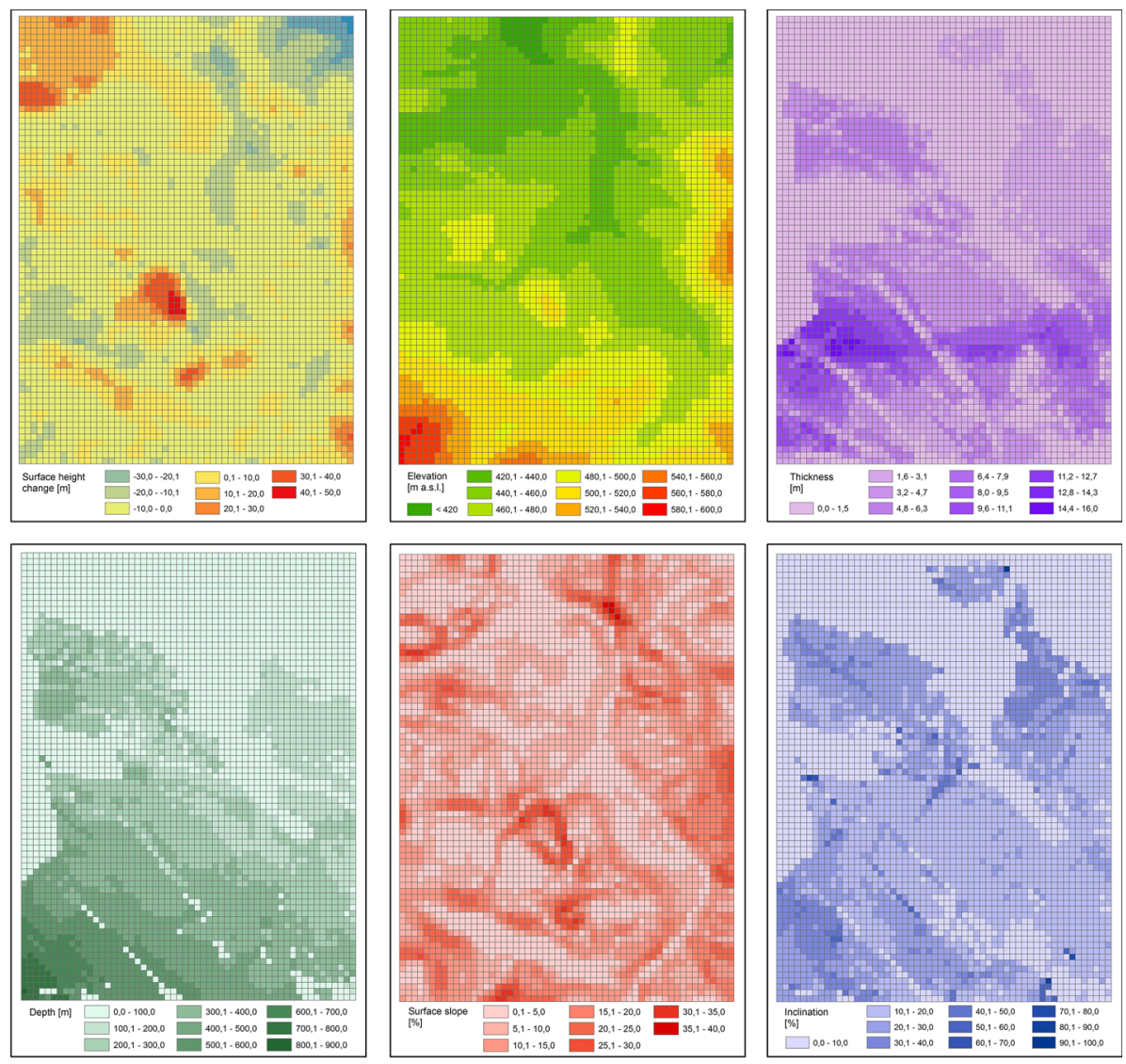

Fig. 4 Spatial representation of dependent and explanatory variables in the regression models 


\subsection{OLS model results}

In the second step, with the assumption of minimum 3 independent variables needed to construct the spatial regression model, all combinations of explanatory independent variables have been tested. Based on the results of exploratory analysis including tests for redundancy (multicollinearity), bias (nonlinear relationships and data outliers) and

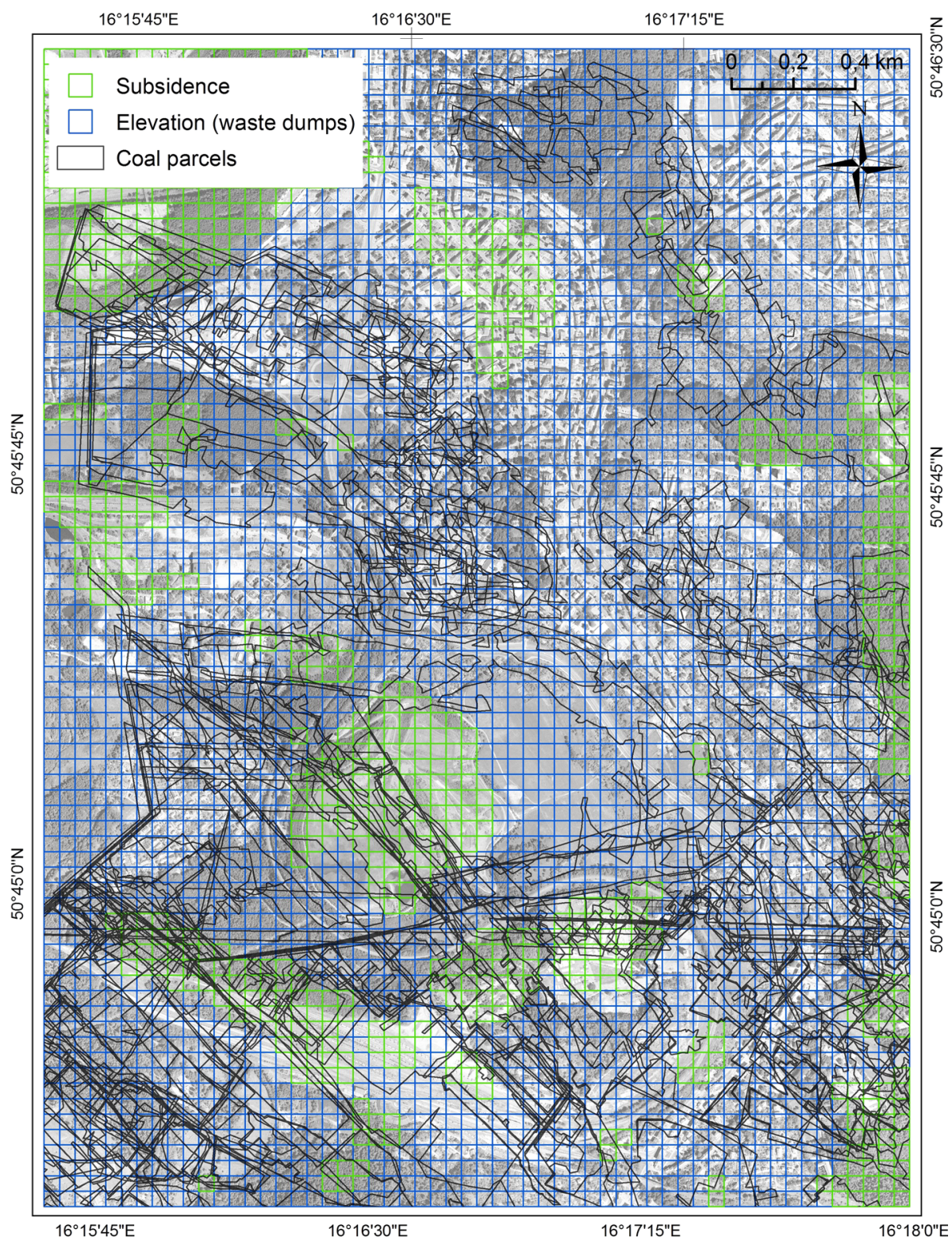

Fig. 5 Extent of the subsidence and elevation areas in the study analysis 
assessment of all possible combination of OLS models, the one with: depth of coal panels, aggregated thickness of coal panels, inclination of coal panels and surface slope explanatory variables has been found to be the best fitting. The selected variables had significant robust probability statistics and also had low variance inflation factor (VIF) values in the range from 1.02 to 2.11 . The VIF is a test of multicollinearity among data, and its values greater than 7.5 indicate that variables are redundant. Summary of the OLS statistics is presented in Table 1. The surface elevation variable explained the same part of the model as the surface slope and the distance from mined coal parcels was found to be insignificant. These two variables have been excluded from further analyses. The OLS model constructed with the four selected variables had the highest value of $R^{2}$ statistic equal to 0.44 and the lowest value of the Akaike information criterion (AICc) statistic equal to 21,688.22. The $R^{2}$ and the AICc are statistics derived from the regression equation to quantify model performance (ESRI 2015). The spatial autocorrelation test run on the model's residuals with the Moran's I showed a slightly clustered pattern. These results, as well as the significant value of the Koenker statistic, which indicates the presence of regional variation in the data, indicated that the global regression model is not efficient to model subsidence related to underground mining in complicated and complex conditions. Therefore, the geographically weighted regression method was applied to study if the model could be improved by taking into account spatial variability of subsidence factors.

\subsection{GWR model results}

In this step, the same set of variables was used to construct a GWR model. The analysed space was divided into a regular $50 \times 50 \mathrm{~m}$ polygon tessellation, and therefore, the "fixed" type of kernel was chosen and the AICc parameter as the bandwidth method to determine the extent of kernel, in accordance with the spatial regression calculation theory. The GWR calculates coefficients for individual features in space, and thus, these can vary and local changes can be captured unlike in the previously analysed global model. The resulting coefficient estimates can be mapped in order to examine local variations in the parameter. In general, each feature estimate has a unique weight matrix, which represents importance of individual observations in the data used to calculate parameters at this location. The closer the observation to this location the greater the weight. The Akaike information criterion is widely used as a diagnostic measure for GWR model fitting.

The results of the GWR analysis showed significantly greater value of the $R^{2}$ statistic equal to 0.69 in comparison with the 0.44 obtained in the OLS analysis. The AICc value for the GWR model was 18,309.52 whereas in the OLS analysis 21,688.22. Greater $R^{2}$ and smaller AICc values indicate that the GWR model is superior to the global regression model and has captured the spatial heterogeneity of independent variables. The spatial autocorrelation test run on the GWR model's residuals with the Moran's I indicated a

Table 1 Summary of the OLS statistics

\begin{tabular}{lrll}
\hline Variable & Coefficient & Probability & VIF \\
\hline Depth & 0.007039 & 0.002582 & 2.112378 \\
Inclination & 0.056196 & 0.030772 & 1.634934 \\
Thickness & 0.002329 & 0.000001 & 1.815144 \\
Slope & -0.023676 & 0.020786 & 1.019823 \\
\hline
\end{tabular}


random pattern with $z$ score of 1.123022 and $p$ value of 0.161428 (Table 2), where $z$ score is standard deviation and $p$ value is probability.

Figure 6 represents the map of standardised residuals in the GWR model. Figure 7 shows maps of coefficients for the independent variables (thickness, depth and inclination of coal panels and surface slope). The blank areas in these maps are regions where the calculated surface change between 1886 and 2009 is positive due to development of new landforms (area of prediction).

Subsequently, the GWR model was used to estimate subsidence in areas with new, positive topographic forms that have developed as the result of industrial development (e.g. waste dumps) causing overall "elevation" of the ground. The maximum subsidence predicted with the GWR model for these parts is $-10.5 \mathrm{~m}$ with the mean subsidence value of $-3.3 \mathrm{~m}$.

The $R^{2}$ statistic of the GWR model equal to 0.69 is a significant improvement in comparison with the global model. The " $69 \%$ " explanation of the phenomenon is influenced by the necessary data simplifications due to the complexity of mining conditions, i.e. averaged depth and inclination of all the coal panels used in the model, accuracy of the subsidence determination for the 1886-2009 period $( \pm 3.0 \mathrm{~m})$ than the model's misspecification. Based on the results of cross-validation, the accuracy of determining subsidence in the first region, where subsidence has been calculated based on cartographic operations (Blachowski and Milczarek 2014) and used as dependent variable in construction of the model is better than $\pm 3.4 \mathrm{~m}$ for all locations with root-mean-square error value of 2.04. The obtained accuracy is a derivative of the propagation of errors associated with quality of source data (e.g. digital coding of mining and topographic maps, cartographic operations used to calculate subsidence) and the mentioned simplifications (i.e. averaged inclination and aggregated thickness, spatial resolution of elementary polygonslocations) that have been adopted to model the complexity of the deposit's geological and mining conditions in this area.

The results obtained in the Walbrzych mine study are consistent with other investigations of subsidence in former coal mining areas (for the depth and surface slope factors) including e.g. fuzzy approach to ground subsidence mapping (Choi et al. 2010), and various statistical and artificial neural network methods (Oh and Lee 2011; Guo et al. 2011; Lee and Park 2013; Mathey 2013; Park et al. 2014). These studies focus predominately on horizontal, single coal seam cases and in none of them, thickness, inclination of exploited coal panels and mining system factors have been considered. The first two of these factors have been found significant for explaining the character of mining subsidence in this study, which concerns multiseam deposit with varying, thickness and inclination of the mined coal panels. These characteristics are difficult to represent due to their complexity and are considered in the literature to also have an effect on mining subsidence (Kratzsch 1983; Knothe 1984; Sinclair Knight Merz 2014). In the Walbrzych study, greater aggregated

Table 2 Global Moran's I summary statistics for GWR model residuals

\begin{tabular}{lr}
\hline Statistic & \multicolumn{1}{c}{ Value } \\
\hline Moran's index & 0.000884 \\
Expected index & -0.000298 \\
Variance & 0.000001 \\
$z$ score & 1.123022 \\
$p$ value & 0.161428 \\
\hline
\end{tabular}




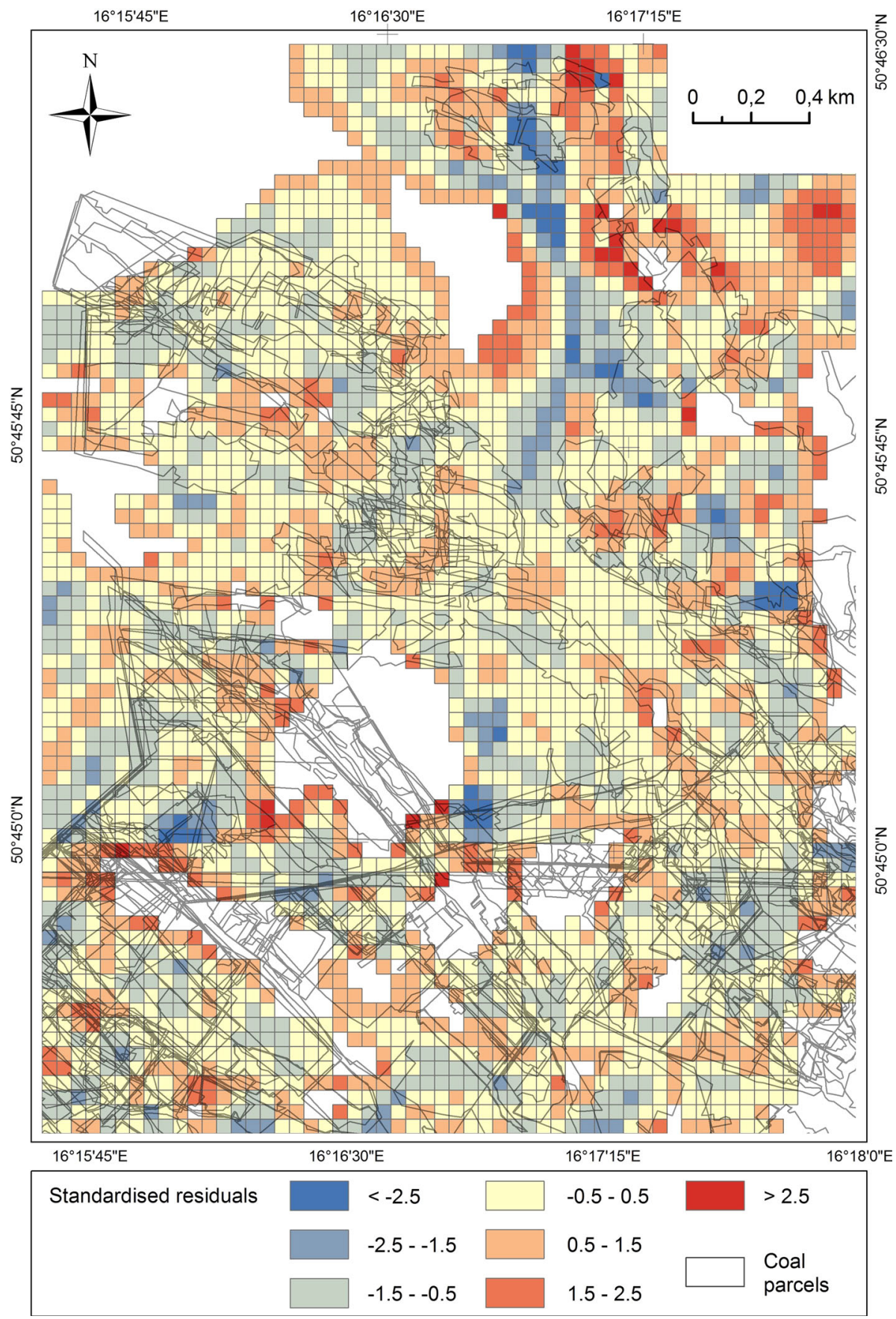

Fig. 6 Map of standardised residuals in the GWR Model 

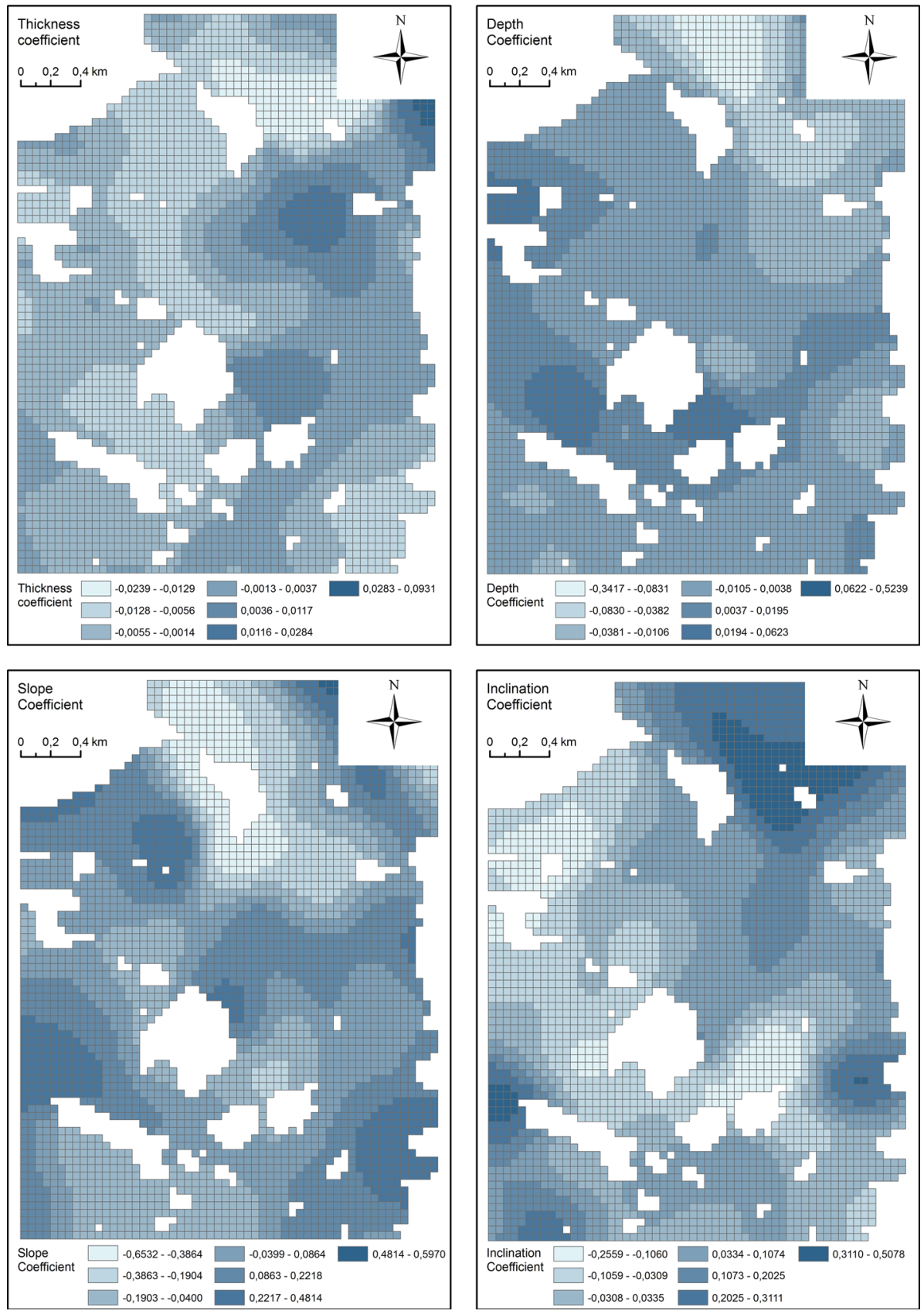

Fig. 7 Maps of coefficients for independent variables

thickness and steeper inclination of coal panels produced higher subsidence values on the surface. Shallow exploitation under valleys and gently sloping areas are also associated with higher values of subsidence. 


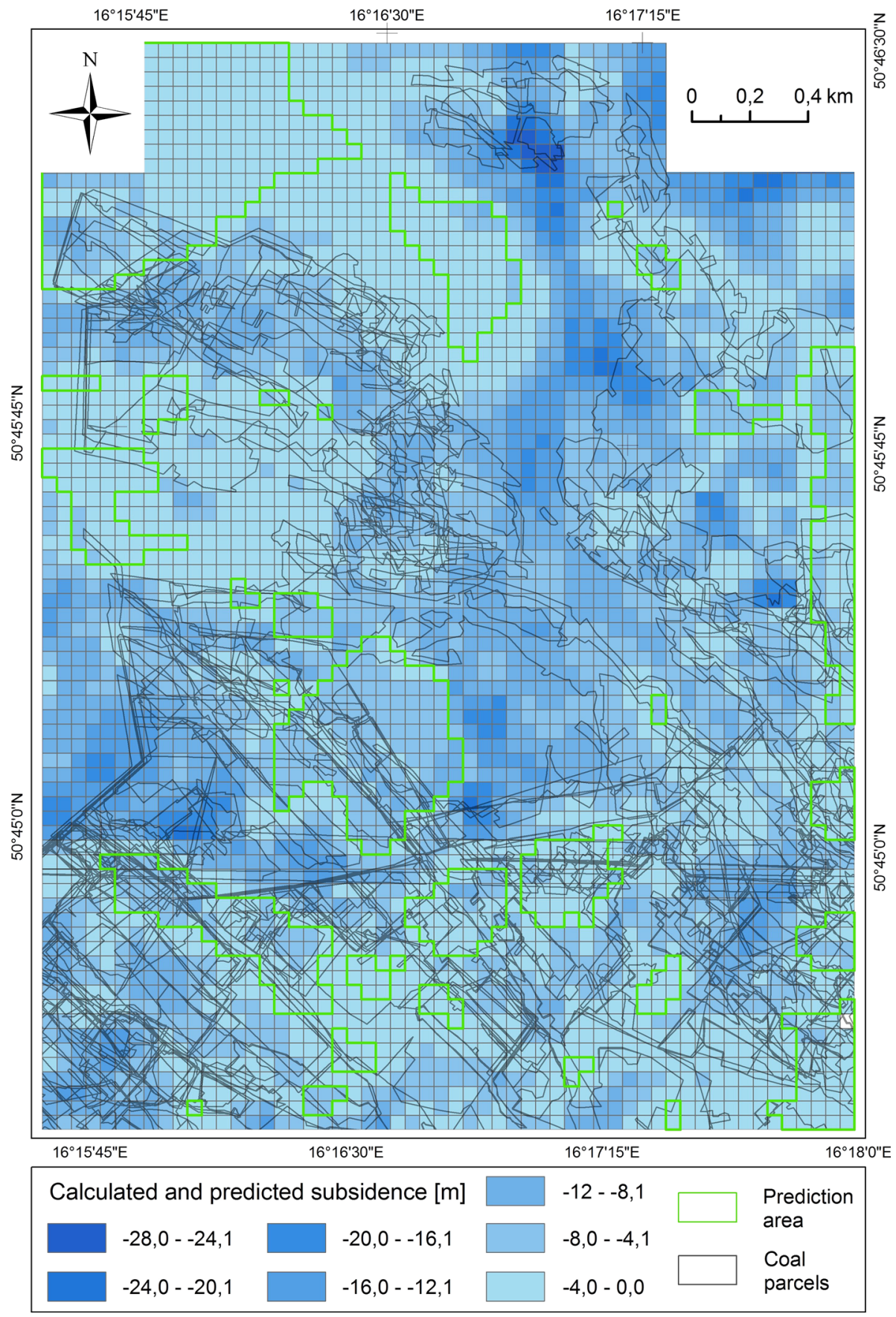

Fig. 8 Hybrid map of calculated subsidence and subsidence predicted for the elevated area 
In the result, mining subsidence map for the 1886-2009 (that is until the end of mining activity and in the post-mining period) has been developed for the first time for the entire area of the Walbrzych mine. It has been developed as a hybrid map of the subsidence calculated from cartographic data processing (Blachowski and Milczarek 2014) and mining subsidence estimated with the validated GWR model using four identified statistically significant independent variables. The final hybrid map presented in Fig. 8 shows the undistorted, by concurrent land transformation, picture of the subsidence basin that developed in consequence of mining for the entire area including parts where it has been concealed by development of new landforms and provides information on the subsidence damage hazard.

The greatest subsidence (marked on the map in darker blue) has occurred in areas with the most complex mining parameters (thickness, inclination) and in areas where the most intensive mining in terms of multiple coal seams took place. Many of these areas are spatially concurrent with mining waste dump sites and other anthropogenic forms of the terrain represented by the zones indicated with green boundaries in Fig. 8.

The proposed approach is an enhancement of mining subsidence and secondary subsidence modelling in complex and complicated mining conditions. The results of this study indicate that the presented method of modelling mining subsidence with weighted spatial regression model is reliable and can be used as an augmentation and alternative to traditional subsidence modelling methods including prediction and assessment of this process in areas with limited amount of surveying data and in cases of complicated mining conditions.

\section{Conclusions}

In the study, a GIS-based multifactorial weighted spatial regression approach has been proposed to model and to analyse mining-related subsidence and the related mining subsidence hazard in former coal mining area characterised by complex and complicated mining conditions. The methodology has been used to develop a spatial model of subsidence and to predict mining subsidence in areas not covered by deformation surveys for the Walbrzych coal mine in the former Walbrzych Coal Basin (SW Poland). The research assessed seven common mining subsidence factors and the following four have been found to be statistically significant: thickness, inclination and depth of coal panels and slope of the surface. The latter two factors are corresponding with findings presented in other studies of mining subsidence concerning simpler conditions, i.e. horizontal, single coal seam mining. The first two factors have not been considered in most of the other published studies and are important for the case of multiseam coal mining and steeply inclined coal panels as in the investigated Walbrzych example.

The accuracy of determining subsidence in area used for validation is $\pm 3.4 \mathrm{~m}$ with the maximum calculated subsidence of $-27.9 \mathrm{~m}$. The maximum subsidence predicted with the model for the unmeasured areas of waste dumps and other new topographic forms is $-10.5 \mathrm{~m}$ with average subsidence of $-3.3 \mathrm{~m}$ during the considered period of mining (1886-2009). The $R^{2}$ value of 0.69 obtained for the best-fitting model indicates good correlation between dependent (subsidence) and independent subsidence factors. The weighted regression model incorporates local variations of factors arising from changing mining conditions and gives better results than the analysed global models. The necessary simplifications of the complex mining conditions, i.e. averaged depth and inclination of the 
14 analysed coal seams adopted in the model and the accuracy of subsidence calculation in the test area $( \pm 3.0 \mathrm{~m})$ (Blachowski and Milczarek 2014) influence the performance of the model as reliable and accurate source data on mining operation and its effects are important for construction of a valid model.

In the result of the study, a hybrid map of mining subsidence for the entire Walbrzych mine area (including unmapped parts) has been developed. The proposed methodology can still be enhanced and used for modelling mining subsidence in any area under the impact of mining and is applicable for complex and complicated mining conditions where it can be an augmentation and alternative to other methods.

Acknowledgments This work has been financed from the Polish National Science Centre project "Development of a numerical method of mining ground deformation modelling in complex geological and mining conditions" No. UMO-2012/07/B/ST10/04297 executed at the Faculty of Geoengineering, Mining and Geology, Wroclaw University of Science and Technology (Poland).

Open Access This article is distributed under the terms of the Creative Commons Attribution 4.0 International License (http://creativecommons.org/licenses/by/4.0/), which permits unrestricted use, distribution, and reproduction in any medium, provided you give appropriate credit to the original author(s) and the source, provide a link to the Creative Commons license, and indicate if changes were made.

\section{References}

Blachowski J, Milczarek W (2014) Analysis of surface changes in the Wałbrzych hard coal mining grounds (SW Poland) between 1886 and 2009. Geol Q 58(2):353-367. doi:10.7306/gq.1162

Blachowski J, Milczarek W, Stefaniak P (2014) Deformation information system for facilitating studies of mining-ground deformations, development, and applications. Nat Hazards Earth Syst Sci 14:1677-1689. doi:10.5194/nhess-14-1677-2014

Bossowski A, Ihnatowicz A (2006) Geological atlas of the Lower Silesian Coal Basin (in Polish). Polish Geological Institute, Warsaw

Brundson Ch, Charlton M, Fotheringham S (1996) Geographically weighted regression: a method for exploring spatial nonstationarity. Geogr Anal 28:4

Can E, Mekik Ç, Kuşcu Ş, Akçın H (2013) Monitoring deformations on engineering structures in Kozlu Hard Coal Basin. Nat Hazards 65:2311-2330. doi:10.1007/s11069-012-0477-x

Charlton M, Fotheringham S (2009) Geographically weighted regression. White paper. National Centre for Geocomputation, National University of Ireland Maynooth

Charlton M, Fotheringham S (2010) Geographically weighted regression. A tutorial on using GWR in ArcGIS 9.3. National Centre for Geocomputation, National University of Ireland Maynooth

Choi JK, Kim KD, Lee S, Won JS (2010) Application of a fuzzy operator to susceptibility estimations of coal mine subsidence in Taebaek City, Korea. Environ Earth Sci 59:1009-1022

de Vent I, Roest H (2013) Lagging mining damage in the Netherlands? Recent signs of soil movement in the Zuid-Limburg coal district. In: Proceedings of the 13th ISM congress, Aachen, Germany, pp 27-41

Doležalová H, Kajzar V, Souček K, Staš L (2009) Evaluation of mining subsidence using GPS data. Acta Geodyn Geomater 6(3):359-367

Doležalová H, Kajzar V, Souček K, Staš L (2012) Analysis of surface movements from undermining in time. Acta Geodyn Geomater 9(3):389-400

Dong S, Samsonov S, Yin H, Yao S, Chong X (2015) Spatio-temporal analysis of ground subsidence due to underground coal mining in Huainan coalfield, China. Environ Earth Sci 73:5523-5534. doi:10.1007/ s12665-014-3806-4

ESRI (2015) ArcGIS Desktop 10.2 Help Library. Spatial Regression

Fotheringham S, Brunsdon C, Charlton M (2002) Geographically weighted regression: the analysis of spatially varying relationships. Wiley, Hoboken

Guo WB, Hou QL, Zou YF (2011) Relationship between surface subsidence factor and mining depth of strip pillar mining. Trans Nonferrous Met Soc China 21:594-598

Huang H, Yu W, Yu Q, Zhang G (2013) Landslide surface deformation analysis based on geographically weighted regression model. EJGE 18:2693-2704 
Kadlečík P, Kajzar V, Nekvasilová Z, Wegmüller U, Doležalová H (2015) Evaluation of the subsidence based on DInSAR and GPS measurements near Karviná, Czech Republic. AUC Geogr 50(1):51-61

Knothe S (1984) Forecasting the influence of mining (in Polish). Ślask Publishing House, Katowice

Kominowski K (2000) Geology and hydrogeology (in Polish). In: Kowalski A (ed) Mining and surface protection. Experiences from the Walbrzych mines. Central Mining Institute, Katowice, pp 33-48

Kowalski A (ed) (2000) Mining and surface protection. Experiences from the Walbrzych mines (in Polish). Central Mining Institute, Katowice

Kożuchowicz S, Oprychał J (1984) Geological documentation of coal deposits in the Walbrzych Hard Coal Mine Walbrzych (in Polish). Przedsiębiorstwo Geologiczne, Wrocław

Kratzsch H (1983) Mining subsidence engineering. Springer, Berlin

Krivoruchko K (2011) Spatial statistical data analysis for GIS Users. ESRI, Redlands

Kumar S, Lal R, Liu D (2012) A geographically weighted regression kriging approach for mapping soil organic carbon stock. Geoderma 189-190:627-634

Kuşcu, S (1991) Mine subsidence monitoring and importance of subject in Zonguldak coal region in Turkey. In: Proceedings FIG international symposium on engineering surveys Sofia, Bulgaria, pp 225-236

Lee S, Park I (2013) Application of decision tree model for the ground subsidence hazard mapping near abandoned underground coal mines. J Environ Manag 127:166-176

Malinowska A (2014) Classification and regression tree theory application for assessment of building damage caused by surface deformation. Nat Hazards 73:317-334. doi:10.1007/s11069-014-1070-2

Mathey M (2013) Addressing the challenges involved with abandoned underground coal mines in South Africa. In: Proceedings of the 13th ISM congress, Aachen, Germany, pp 113-123

Oh HJ, Lee S (2011) Integration of ground subsidence hazard maps of abandoned coal mines in Samcheok, Korea. Int J Coal Geol 86:58-72

Park I, Lee J, Lee S (2014) Ensemble of ground subsidence hazard maps using Fuzzy Logic. Cent Eur J Geosci 6(2):207-218. doi:10.2478/s13533-012-0175-y

Popiołek E (2009) Protection of mining terrains (in Polish). AGH Publishing House, Cracow

Raucoules D, Maisons Ch, Carnec C, Le Mouelic S, King Ch, Hosford S (2003) Monitoring of slow ground deformation by ERS radar interferometry on the Vauvert salt mine (France). Comparison with groundbased measurement. Remote Sens Environ 88:468-478

Samsonov S, d'Oreyeb N, Smets B (2013) Ground deformation associated with post-mining activity at the French-German border revealed by novel InSAR time series method. Int J Appl Earth Obs Geoinf 23:142-154

Sedlak V (2015) Some specific procedures in solving the deformation vector for mining undermined areas. J Mater Eng Struct 2:99-110

Shang RK, Shiu YS, Ma KC (2011) Using geographically weighted regression to explore the spatially varying relationship between land subsidence and groundwater level variations: a case study in the Choshuichi alluvial fan, Taiwan. IEEE, pp 21-25

Sinclair Knight Merz Pty Ltd (2014) Subsidence from coal mining activities. Department of the Environment, Australian Government

Stecchi F, Mancini F, Ceppi C, Gabbianelli G (2012) Vulnerability to ground deformation phenomena in the city of Tuzla (BiH): a GIS and multicriteria approach. Nat Hazards 64:2153-2165. doi:10.1007/ s11069-012-0225-2

Wójcik J (2008) Surface change due to mining in the Walbrzych area (in Polish with English summary). Landf Anal 9:339-342 